\title{
Identifikasi Potensi Desa Wisata Sangeh, Kabupaten Badung
}

Dean Dionisius Beoang a, 1, Ida Ayu Suryasih a, 2

1dionisiusdean@ymail.com, 2idaayusuryasih@unud.ac.id

a Program Studi S1 Destinasi Pariwisata, Fakultas Pariwisata,Universitas Udayana, Jl. Dr. R. Goris, Denpasar, Bali 80232 Indonesia

\section{Abstract}

Bali has various tourism potentials both natural and cultural which yet to be explored and identified further in order to be developed to become tourist attractions, with feasible facilities available that can be offered. Sangeh Village is one of tourist villages in Badung Regency which has various tourism potentials and one of it is Tourist Attraction of Alas Pala Sangeh. In addition there are still many other tourism potentials which are yet to be developed and promoted optimally. Therefore this research was conducted to identify tourism potentials existed at Tourist Village of Sangeh.

The method being used in this research was qualitative method with data sampling technique through observations, in depth interviews, and literature studies so that able to identify tourism potentials existed at Tourist Village of Sangeh.

The result of this research shows that the Village of Sangeh is one of customary villages in Bali which has various tourism potentials so that the Village of Sangeh is called a Tourist Village. The potentials owned by Tourist village of Sangeh is in the form of physical and non-physical potentials. Physical potentials referred to among others are Tourist Garden of Mumbul, Tourist Attraction of Alas Pala Sangeh and Pondok Jaka, whereas non-physical potential is Trekking activity managed by POKDARWIS Bukit Sari Sangeh, an institution that supervise Sangeh Traditional Activity. This research aims to identificate potentials of tourism available in Tourist Village of Sangeh.

\section{Keywords: Identification, Tourism Potential, and Tourism Village}

\section{PENDAHULUAN}

Pulau Bali terkenal akan keindahan alam yang dimiliki, oleh karena itu banyak potensi potensi wisata yang dikembangkan menjadi daya tarik wisata agar dapat menarik wisatawan untuk berkunjung ke Bali. Namun saat ini, pariwisata di Bali tidak hanya mengandalkan potensi alam saja karena banyak wisatawan baik lokal maupun mancanegara yang tertarik terhadap kebudayaan, adat istiadat bahkan kehidupan sosial masyarakat di Bali. Hal ini menjadikan Pulau Bali sebagai salah satu tujuan wisata utama di Indonesia sehingga Provinsi Bali dapat menyumbangkan pendapatan negara yang cukup besar melalui sektor pariwisata.

Dengan bermodalkan keindahan alam dan budaya yang masih kental, Bali memiliki banyak sekali potensi wisata baik alam maupun budaya yang masih harus digali dan diidentifikasi lebih dalam agar dapat dikembangkan lagi menjadi daya tarik wisata, dengan fasilitas -fasilitas yang layak tersedia didalamnya.

Desa Wisata Sangeh adalah salah satu desa wisata di Kabupaten Badung yang memiliki berbagai potensi wisata salah satunya adalah Daya Tarik Wisata Alas Pala Sangeh. Selain itu masih banyak potensi wisata lainnya yang belum dikembangkan dan dipromosikan secara optimal. Oleh karena itu penelitian ini dilakukan untuk mengidentifikasi potensi potensi wisata yang ada di Desa Wisata Sangeh.

\section{TINJAUAN PUSTAKA}

1. Konsep Potensi Wisata

Potensi Wisata adalah sesuatu yang dimiliki oleh suatu daya tarik wisata yang menjadi aset dalam melakukan upaya pengembangan daerah tujuan wisata tersebut, dengan demikian hal itu dapat digunakan untuk meningkatkan ekonomi masyarakat sekitar dan menambah pendapatan daerah. Secara umum terdapat 3 jenis potensi wisata yaitu : (1) Potensi Alam, yaitu kondisi alam yang ada di suatu tempat atau keadaan fisik suatu tempat wisata; (2) Potensi Kebudayaan, yaitu potensi yang didapatkan dari hasil karya diciptakan langsung oleh masyarakat lokal di daerah tersebut serta peninggalan - peninggalan sejarah yang ada di suatu daerah; (3) Potensi Manusia, yaitu atraksi - atraksi wisata yang dipertunjukkan atau yang dipentaskan langsung oleh masyarakat lokal setempat. Dalam penelitian ini potensi wisata dibagi menjadi dua yaitu potensi fisik dan potensi non fisik (Yoeti, 2008).

2. Konsep Desa Wisata

Desa wisata adalah suatu bentuk integrasi antara atraksi, akomodasi dan fasilitas 
pendukung yang disajikan dalam suatu struktur kehidupan masyarakat yang menyatu dengan tata cara dan tradisi yang berlaku (Nuryanti,1993). Desa Wisata didefinisikan sebagai sebagian atau keseluruhan wilayah desa yang dimiliki potensi, produk dan aktivitas wisata yang dapat dimanfaatkan untuk pengembangan pariwisata dan dikelola oleh kelompok masyarakat di desa secara berkelanjutan (Suryawan, 2015).

\section{METODE PENELITIAN}

Penelitian ini dilakukan di Desa Wisata Sangeh, Kecamatan Abiansemal, Kabupaten Badung dan berjarak sekitar $25 \mathrm{Km}$ dengan waktu tempuh sekitar 30 menit dari kota Denpasar. Desa Wisata Sangeh terletak pada jalur strategis kegiatan pariwisata DenpasarPetang-Kintamani. Penelitian ini mengambil Desa Wisata Sangeh sebagai lokasi penelitian karena Desa Wisata Sangeh memiliki berbagai potensi wisata selain Daya Tarik Wisata Alas Pala Sangeh.

Dalam penelitian ini yang dimaksud dengan mengidentifikasi potensi wisata adalah untuk mengetahui potensi - potensi apa saja yang ada di kawasan Desa Wisata Sangeh. Jenis data yang digunakan dalam penelitian ini yaitu data kualitatif, yaitu data berupa gambaran umum Desa Wisata Sangeh, keterangan-keterangan yang diperoleh dari hasil wawancara tentang permasalahan yang diteliti, lokasi penelitian, serta informasi mengenai sejarah yang tersimpan dari suatu potensi wisata yang ada di Desa Wisata Sangeh.

Sumber data yang di gunakan dalam penelitian ini adalah data primer dan data sekunder. Data primer yang dimaksud adalah wawancara dengan pihak yang terkait yakni ketua POKDARWIS Desa Wisata Sangeh dan beberapa masyarakat lokal Desa Wisata Sangeh yang ikut berpartisipasi dalam proses pembentukan Desa Wisata Sangeh. Data sekunder yang dimaksud dalam penelitian ini adalah berupa profil Desa Wisata Sangeh.

Metode pengumpulan data yang dilakukan dalam penlitian ini adalah dengan observasi, wawancara, dan studi dokumentasi. Observasi dilakukan untuk mengetahui keadaan langsung di lapangan. Wawancara dilakukan dengan pengelola Desa Wisata Sangeh untuk melengkapi hasil penelitian di lapangan.
Penentuan informan dalam penelitian ini memakai Purposive Sampling. Purposive Sampling adalah teknik pengambilan sampel dengan pertimbangan tertentu. Pertimbangan tertentu yang dimaksudkan adalah orang tersebut yang dianggap paling tahu tentang apa yang kita harapkan, atau mungkin dia sebagai penguasa sehingga akan memudahkan menjelajahi obyek/situasi sosial yang diteliti (Sugiyono, 2009).

Dalam penelitian ini digunakan pendekatan deskriptif kualitatif yaitu menggambarkan suatu fenomena, kemudian mengkaitkannya dengan fenomena lainnya melalui interprestasi untuk dideskripsikan dalam suatu kualitas yang mendekati kenyataan (Khaldun, 2008). Nasution (1998) menyatakan analisis telah mulai merumuskan dan menjelaskan masalah, sebelum terjun ke lapangan, dan berlangsung terus menerus sampai penulisan hasil penelitian. Dari pemahaman pola yang dipaparkan di atas, adapun fenomena yang ditemukan dilapangan yaitu menggambarkan dengan jelas mengenai gambaran umum dan potensi - potensi di Desa Wisata Sangeh.

\section{HASIL DAN PEMBAHASAN}

\subsection{Kondisi Geografis}

Desa Wisata Sangeh adalah sebuah desa wisata yang terletak di Kecamatan Abiansemal, Kabupaten Badung, Provinsi Bali dan memiliki batas wilayah sebagai berikut:

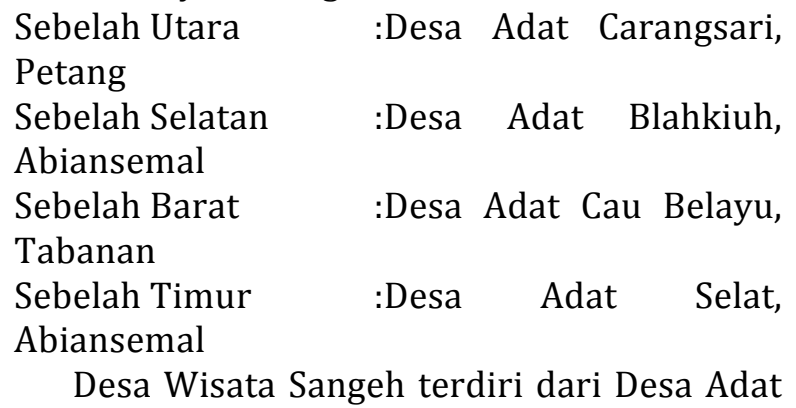
Sangeh dan Desa Adat Grana serta memiliki luas wilayah 450 Hektar. Desa Wisata Sangeh juga memiliki 7 banjar dinas antara lain : Pemijian, Sibang, Brahmana, Muluk Babi, Batusari, Pacung dan Tegal Grana. Kepadatan penduduk Desa Wisata Sangeh kurang lebih 976 per $\mathrm{Km}^{2}$ (Sumber : Wawancara dengan Bendesa Adat Sangeh, 2016).

\subsection{Potensi Desa Wisata Sangeh}

Desa Wisata Sangeh memiliki beberapa potensi wisata yang menjadi daya tarik tersendiri. Tidak hanya memiliki potensi akan 
fauna yaitu monyet abu - abu yang menjadi daya tarik alam utama, tetapi juga potensi flora seperti Pohon Pala/Keruing. Potensi - potensi wisata lain yang dimiliki Desa Wisata Sangeh antara lain :

\section{Taman Wisata Mumbul}

Lokasi Taman Wisata Mumbul terletak di area Desa Wisata Sangeh dan berjarak sekitar 500 M dari Daya Tarik Wisata Alas Pala Sangeh. Taman Wisata Mumbul dapat ditempuh selama 20 menit dari Kota Denpasar.

Pengembangan Taman Mumbul merupakan gagasan yang diajukan oleh POKDARWIS Bukit Sari agar potensi di Desa Wisata Sangeh menjadi bertambah. Sejauh ini Taman Mumbul dimanfaatkan sebagai sumber air dan menjadi kolam pancing bagi wisatawan yang berkunjung. Potensi utama antara lain : air yang terus mengalir sepanjang tahun, kegiatan ritual, pemandangan yang sangat menarik, bentuk bangunan tradisional Bali, keasrian alam, lingkungan yang sangat cocok untuk yoga, adat dan tradisi yang masih dilestarikan, serta jaraknya tidak terlalu jauh dari Kota Denpasar.

Karena Taman Mumbul memiliki sumber air yang melimpah, maka pihak pengelola berinisiatif untuk menjadikan Taman Mumbul menjadi tempat wisata taman air yang dapat dinikmati oleh wisatawan. Kawasan Taman Wisata Mumbul adalah sebuah kawasan hijau yang masih alami karena banyak ditumbuhi oleh tumbuh - tumbuhan.

Taman Wisata Mumbul terbagi menjadi 3 bagian, yaitu:

a. Utama Mandala, atau bagian terdalam dari Taman Wisata Mumbul dan juga merupakan area suci yang digunakan untuk Melasti, Nyegara Gunung, Ngening, Upacara Pitra Yadnya, dan Magpag Toya.

b. Madya Mandala, atau bagian tengah dari Taman Wisata Mumbul. Didalamnya terdapat Bale Kulkul, Wantilan, Bale Pesandekan, Bale Gong, dan Perantenan. Area ini biasanya digunakan untuk Melukat, Yoga, serta panggung terbuka untuk pertunjukkan seni dam budaya.

c. Nista Mandala, atau bagian paling luar dari Taman Wisata Mumbul. Area ini cukup luas untuk pertunjukkan tari tarian dan tempat untuk mempersiapkan upacara - upacara keagamaan. Selain itu juga terdapat kolam renang, kolam pancing, restoran, lazy river, taman landscape, dan menara luncur.

Masyarakat Desa Wisata Sangeh sendiri menganggap bahwa Taman Mumbul ini merupakan tempat suci dan juga tempat bagi umat Hindu untuk melakukan kegiatan keagamaan seperti Upacara Melasti. Taman Mumbul sering dikunjungi oleh wisatawan yang menyukai suasana yang tenang dan nyaman karena Taman Mumbul juga berlokasi cukup jauh dari jalan raya.

\section{Daya Tarik Wisata Alas Pala Sangeh}

Hingga saat ini belum ada sejarah yang pasti mengenai terbentuknya Daya Tarik Wisata Alas Pala Sangeh, cerita - cerita yang tersebar hanya berdasarkan cerita yang diyakini oleh masyarakat lokal Desa Adat Sangeh. Desa Adat Sangeh memiliki sebuah legenda yang menceritakan bahwa seorang putri dari Ida Bathara ring Gunung Agung harus mendapatkan hukuman yang cukup lama atas kesalahan yang telah dilakukannya. Sang Putri ingin kembali ke rumahnya setelah masa hukumannya tersebut berakhir. Diperjalanan pulang pun Putri dikawal oleh hewan - hewan seperti kera, ular, dan macan. Namun pada saat diperjalanan, Putri melihat sesuatu yang tidak dapat dipercaya, yaitu sebuah hutan (alas) sedang berjalan dihadapannya.

Setelah melihat hutan itu Sang Putri justru ingin tinggal di hutan tersebut dan tidak jadi kembali ke Gunung Agung. Putri tinggal di hutan itu bersama dengan sekawanan hewan yang mengikutinya dari tempat ia dihukum, yaitu Pulaki. Keberadaan Pura Bukit Sari yang terletak ditengah - tengah hutan pala adalah untuk memuja Sang Putri dan Ida Bathara Gunung Agung. Sebuah daerah bernama Alas Siga yang terletak disebelah selatan hutan tersebut adalah bukti dari adanya legenda tersebut.

Masyarakat lokal Desa Adat Sangeh mempercayai bahwa kera - kera yang ada di hutan adalah keturunan dari kera yang tinggal di hutan tersebut bersama Sang Putri pada jaman dahulu, selain itu juga terdapat macan kuning dan macan hitam yang menghuni hutan pala dan seringkali muncul pada saat perayaan piodalan di Pura Bukit Sari. Kata "Sangeh" 
berasal dari penggabungan dua kata yaitu "Sang" dan "Ngeh" yang memiliki arti "Melihat".

Hal ini dikarenakan adanya sebuah cerita dimana Hutan Pala menempuh perjalanan kea rah barat dari Gunung Agung, kemudian Hutan Pala tersebut berhenti di suatu tempat untuk beristirahat. Tempat tersebut adalah tempat yang sekarang diberikan nama Sangeh ( Sumber : www.bukit-sarisangeh.com ).

Daya Tarik Wisata Alas Pala Sangeh ini didirikan pada 1 Januari 1969. Namun tahun 1972 dilakukan pengembangan dimana dana yang digunakan untuk melakukan pengembangan ini adalah berasal dari dana retribusi yang diberikan oleh para wisatawan yang datang untuk berkunjung ke Daya Tarik Wisata Alas Pala Sangeh. Desa Adat Sangeh membentuk suatu organisasi dimana karyawan - karyawan yang terdapat di dalamnya merupakan masyarakat lokal. Organisasi ini dibentuk untuk mengelola Daya Tarik Wisata Alas Pala Sangeh. Sejak tahun 1990an Daya Tarik Wisata Alas Pala Sangeh sudah menjadi salah satu destinasi pilihan wisatawan karena memiliki pemandangan yang sangat indah yakni penggabungan dari potensi flora dan fauna serta keindahan budaya yang terdapat didalamnya. Daya tarik Wisata Alas Pala Sangeh memiliki luas sekitar 14 Hektar yang didominasi oleh Pohon Pala yang mencapai luas hingga 10 Hektar. Pohon Pala yang ada di Daya Tarik Wisata Aaas Pala Sangeh sudah berusia ratusan tahun, tingginya mencapai 70 meter dan memiliki diameter berukuran 2 meter. Selain itu, 600 ekor kera berwarna abu - abu yang ada di Daya Tarik Wisata Alas Pala Sangeh juga menjadi daya tarik alam utama tersendiri. Biaya yang harus dikeluarkan untuk bias menikmati Daya Tarik Wisata Alas Pala Sangeh cukup terjangkau bagi semua kalangan. Untuk wisatawan lokal akan dikenakan tiket masuk sebesar Rp 5.000 untuk anak - anak dan Rp 10.000 untuk dewasa. Sedangkan wisatawan mancanegara akan dikenakan tiket masuk sebesar Rp 10.000 untuk anak - anak dan Rp 15.000 untuk dewasa (Profil POKDARWIS Bukit Sari Sangeh, 2016).

Pada saat memasuki Daya Tarik Wisata Alas Pala Sangeh terdapat sebuah patung raksasa yang berwujud kesatria yang disebut Kumbakarna. Patung ini seringkali dijadikan sebagai tempat berfoto wisatawan, karena selain memiliki bentuk yang indah patung ini juga memiliki cerita yang menggambarkan cerita Ramayana yang sangat terkenal. Selain melakukan kegiatan wisata, di Daya Tarik Wisata Alas Pala Sangeh juga terdapat Pura Bukit Sari, Pura Melanting, Pura Tirta, dan Pura Anyar yang dijadikan sebagai tempat ibadah untuk umat Hindu.

Walaupun sudah terdapat beberapa daya tarik wisata serupa namun hingga saat ini Daya Tarik Wisata Alas Pala Sangeh tetap ramai dikunjungi oleh wisatawan karena keunikan dan keindahan tersendiri dari potensi yang dimiliki.

Terdapat juga para wisatawan yang berkunjung ke Daya Tarik Wisata Alas Pala Sangeh ini hanya ingin melihat dan mengetahui mengenai sejarah Pohon Pala yang ceritanya cukup terkenal. Selain memiliki bentuk yang unik, Pohon Pala ini juga dikabarkan tidak dapat ditanam ditempat lain sehingga tidak ada satu orang pun yang dapat memiliki kayu dari Pohon Pala tersebut. Selama bertahun - tahun Pohon Pala tersebut tidak pernah ditebang sama sekali, karena masyarakat setempat memiliki kepercayaan jika pohon tersebut ditebang maka malapetaka atau kutukan akan menimpa orang yang menebangnya.

\section{Pondok Jaka}

Masyarakat lokal Desa Wisata Sangeh memiliki rumah - rumah tradisional khas Bali yang digunakan untuk menjadi salah satu potensi wisata yang ada di Desa Wisata Sangeh untuk menarik wisatawan. Rumah tradisional ini disebut Pondok Jaka yang sudah ada sejak ratusan tahun lalu, namun saat ini terdapat 1 unit Pondok Jaka yang masih dirawat oleh pihak Desa Wisata Sangeh. Pondok Jaka adalah tempat untuk memulai aktivitas trekking bagi para wisatawan, selain itu juga digunakan untuk beristirahat sejenak dan menikmati makan siang. Tidak hanya menikmati makan siang, tetapi wisatawan juga dapat belajar memasak masakan khas Bali yang akan diajarkan langsung oleh masyarakat lokal yang ada disana. Selain itu Pondok Jaka juga sering dijadikan sebagai sanggar tari untuk wisatawan yang ingin mempelajari tarian tradisional Bali. Kegiatan memasak dan menari tersebut tidak dikenakan biaya sama sekali. Banyak orang orang yang datang baik dari Bali maupun dari luar Bali ke Pondok Jaka ini untuk melakukan hunting foto atau foto prawedding. Untuk 
penyediaan jasa foto prawedding dikenakan biaya sebesar Rp 750.000,-.

\section{Aktivitas Trekking}

Aktivitas Trekking merupakan aktivitas yang dibentuk oleh pihak Desa Adat Sangeh untuk memanfaatkan potensi Wisata selain potensi alam yang ada di Desa Wisata Sangeh agar wisatawan dapat melakukan suatu aktivitas selama menikmati potensi wisata alam lainnya. Untuk menjalankan aktivitas Trekking ini, Desa Adat Sangeh bekerjasama dengan Sangeh Traditional Activity, yaitu organisasi yang dinaungi oleh POKDARWIS Bukit Sari. Ide untuk membentuk aktivitas Trekking ini karena melihat lingkungan sekitar Desa Wisata Sangeh yang indah, sehingga jalur yang digunakan untuk melakukan trekking adalah jalan setapak yang melewati persawahan, dan melalui air terjun yang ada di kawasan Desa Sangeh sehingga wisatawan akan mendapatkan pengalaman yang menarik. Di lintasan trekking ini wisatawan akan menemukan batu - batu besar yang seringkali dijadikan tempat untuk melakukan yoga. Untuk paket aktivitas trekking ini pengunjung dikenakan harga Rp 600.000/orang, harga paket ini juga sudah termasuk mendapatkan makan siang di Pondok Jaka. Selain melakukan trekking wisatawan juga dapat bersepeda atau cycling dengan melalui jalan aspal mengelilingi persawahan yang ada di Desa Wisata Sangeh.

\section{SIMPULAN DAN SARAN}

\subsection{Simpulan}

Suatu daerah dapat dikatakan sebagai daya tarik wisata jika daerah tersebut memiliki potensi - potensi wisata yang menjadi aset untuk melaksanakan upaya pengembangan kepariwisataan sehingga dapat menarik wisatawan untuk berkunjung. Desa Sangeh adalah salah satu desa adat di Bali yang memiliki berbagai potensi wisata sehingga Desa Sangeh disebut sebagai Desa Wisata. Potensi potensi yang dimiliki oleh Desa Wisata Sangeh berupa potensi fisik dan potensi non fisik. Potensi fisik yang dimaksud antara lain Taman Wisata Mumbul, Daya Tarik Wisata Alas Pala Sangeh dan Pondok Jaka, sedangkan potensi non fisik tersebut adalah aktivitas Trekking yang dikelola oleh POKDARWIS Bukit Sari Sangeh dan menaungi Sangeh Traditional
Activity. Selain memiliki keindahan alam, potensi wisata yang ada di Desa Sangeh juga terkenal dengan sejarah dan misterinya. Hal tersebut merupakan salah satu faktor yang menarik wisatawan untuk datang berkunjung.

\subsection{Saran}

Pengelola Desa Wisata Sangeh harus bersinergi dengan banjar yang ada di Desa Adat Sangeh dalam perencanaan pengembangan Desa Wisata Sangeh. Pihak pengelola Desa Wisata Sangeh juga perlu mengadakan kerjasama - kerjasama dengan biro perjalanan wisata atau travel agent agar dapat mengoptimalkan promosi sehingga dapat meningkatkan jumlah kunjungan wisatawan yang berkunjung ke potensi -potensi yang ada di Desa Wisata Sangeh. Studi yang lebih lanjut perlu dilakukan mengenai pengelolaan oleh Desa Adat Sangeh yang dilakukan secara optimal.

\section{Daftar Pustaka:}

Khaldun, Ibn. 2008. "Muqaddimah Ibn Khaldun". Diterjemahkan oleh Ahmadie Thoha, Muqaddimah Ibn Khaldun. Jakarta: Pustaka Firdaus, 2008.

Nasution, 1998. Metodologi Penelitian Kualitatif. Bandung: Tarsito.

Nuryanti, Wiendu, 1993. Concept, Perspective and Challenges, Makalah Bagian dari Laporan Konferensi Internasional mengenai Pariwisata Budaya. Yogyakarta, Gadjah Mada University Pess.

Sugiyono. 2009. Metode Penelitian Bisnis (Pendekatan Kuantitatif, Kualitatif, dan R\&D). Alfabeta. Bandung

Suryawan, Ida Bagus. 2015. Perkembangan dan Pengembangan Desa Wisata. Depok: Herya Media

Yoeti, Oka.A. 2008. Perecanaan dan Pengembangan Pariwisata. Pradnya Paramita: Jakarta.

Sumber Internet:

http://blogsangeh.blogspot.com/2013/07/profil-desasangeh.html. Diakses tanggal 3 Mei 2016

www.bukit-sari-sangeh.com. Website Daya Tarik Wisata Alas Pala Sangeh Kabupaten Badung. Diakses tanggal 3 Mei 2016 